\title{
Isokinetic Strength, Bilateral and Unilateral Strength Differences: Variation by Age and Laterality in Elite Youth Football Players
}

\author{
Fuerza Isocinética, Diferencias de Fuerza Bilaterales y Unilaterales: \\ Variación por Edad y Lateralidad en Futbolistas Juveniles de Élite \\ Tomas Maly ${ }^{1}$; Kevin R. Ford²; Dai Sugimoto ${ }^{3,4}$; Jana Izovska'; ${ }^{1}$ David Bujnovsky'; \\ Mikulas Hank ${ }^{1}$; Lee Cabell ${ }^{5}$ \& Frantisek Zahalka ${ }^{1}$
}

\begin{abstract}
MALY, T.; FORD, K. R.; SUGIMOTO, D.; IZOVSKA, J.; BUJNOVSKY, D.; HANK, M.; CABELL, L. \& ZAHALKA, F. Isokinetic strength, bilateral and unilateral strength differences: variation by age and laterality in elite youth football players. Int. J. Morphol., 39(1):260-267, 2021.
\end{abstract}

SUMMARY: The purpose of this study was to investigate the effect of age on peak torque (PT) relative strength measures of knee extensors $(\mathrm{KE})$ and knee flexors $(\mathrm{KF})$, bilateral strength ratio $(\mathrm{Q}: \mathrm{Q}, \mathrm{H}: \mathrm{H})$, and ipsilateral strength ratio $(\mathrm{H}: \mathrm{Q})$ in youth elite male football players.Elite male players $(n=70)$ from four age categories (U16: $n=20$, U17: $n=20, U 19: n=15, U 21: n=15)$ performed isokinetic strength tests using a Cybex dynamometer. Results show a significant effect of age on PTKE $(\mathrm{F} 3,142=4.54, \mathrm{p}=0.005,=$ 0.09 ) and PTKF (age: F3,142 =3.07, p = 0.030, = 0.06). No significant effect of age on unilateral $(\mathrm{F} 3,142=1.05, \mathrm{p}=0.375,=0.02)$ or ipsilateral strength ratio $(\mathrm{F} 3,142=2.63, \mathrm{p}=0.053,=0.06)$ was found. Results revealed significant differences in PTKE for nondominant limbs between U16 and U21. Higher bilateral differences were detected for flexors (H:H=7.94-11.47 \%, Q:Q = 7.97-9.29\%) compared to extensors. Our study showed that 17-year-old players have levels of strength similar to U19 players. A higher bilateral difference of knee flexors than extensors was found, suggesting that more attention should be paid to knee flexors. No effect of laterality was found for strength and strength asymmetries. Future research should also focus on ipsilateral strength ratio in late stage of maturation.

KEY WORDS: Soccer; Performance; Strength asymmetries; Injury prevention.

\section{INTRODUCTION}

Asymmetric movement patterns and their repetitive character in sports like football naturally force players to use one dominant lower limb for kicking, cutting, or body support. Thus, the strength ratio symmetricity and their agonist/antagonist muscle performance is by nature of the sport unbalanced and can gradually cause maladaptive changes (Fousekis et al., 2010; Maly et al., 2019). It is very important during this sensitive period of growth that strength symmetricity is under supervision. As football training improves some strength aspects of the lower limbs on its own, additional resistance training provides a positive and significant increase in lower and upper body strength, sprinting, and jumping abilities (Lehance et al., 2009). According to Iga et al. (2009), football players almost never use both legs with the same emphasis, and this preference is related to hemispheric brain dominance, which may be the cause of some strength deficit in professional football players.

Muscular strength (MS) is considered a primary component of an athlete's physical fitness (Suchomel et al., 2016). MS alterations occur during childhood and adolescence, which may progress differently in terms of variations over time between individuals, muscle groups, types of muscle action, and development of the nervous system (Lloyd et al., 2014). Increasing MS and its dynamic qualities through strength training has shown distinct improvements in the contractile rate of force development and power impulse, thus reaching greater efferent neural drive of the muscle, which is of great significance for athletes (Aagaard et al., 2002). This gain also improves sprinting and jumping (Zahalka et al., 2016); acceleration,

\footnotetext{
${ }^{1}$ Faculty of Physical Education and Sport, Charles University, Prague 16252, Czech Republic.

${ }^{2}$ Department of Physical Therapy, High Point University, High Point, NC 27268, USA.

${ }^{3}$ Faculty of Sport Sciences, Waseda University, 2 Chome-7-5, Higashi-Fushimi, Nishi-Tokyo city, Tokyo 202-0021, Japan.

${ }^{3}$ The MicheliCenter for Sports Injury Prevention, 9 Hope Ave Waltham, MA 02453, USA

${ }_{5}^{5}$ Department of Health and Human Performance, Texas State University, San Marcon, TX 78666, USA.
} 
deceleration, and changing direction (Clemente, 2016); and other football-specific skills (Maly et al., 2018). Additionally, lack of hamstring power endangers the technique of impact in adolescents, leading to high-risk biomechanical movement patterns (Wild et al., 2013).

Long-term participation in football also leads to the development of various degrees and modes of functional asymmetries (Fousekis et al.). MS deficiency and strength asymmetry has been proposed as one of the several risk factors for injury in football (Maly et al., 2016; Xaverova et al., 2015) andit is documented that greater MS reduces this potential injury risk (Bourne et al., 2015; Suchomel et al.).

To the best of our knowledge, there is a lack of studies evaluating the isokinetic strength of elite (leader of highest national league) youth football players in the period of maturation with expression strength as relative values (relative to body weight).Therefore, the current study aimed to investigate the effect of limb dominance and age through relative strength measures of knee extensors/flexors and bilateral/ipsilateral strength ratios in youth elite male football players. We hypothesised that there is a: (a) significant difference of isokinetic strength based on age, (b) non-significant effect of age on the level of strength asymmetries, c) non-significant effect of laterality on the level of muscle strength and ipsilateral ratio, and d) significantly higher bilateral strength deficiency in knee flexors compared to extensors.

\section{MATERIAL AND METHOD}

Study design. A cross-sectional design was used. We explained the study to all participants prior to commencing the study. Informed consent was signed and collected from participants and parents of participants who were not over 18 years old. The study was approved by the Ethical Committee of the Faculty of Physical Education and Sport, Charles University, in Prague, Czech Republic (Nr. 101/ 2018). The ethical documents were prepared in accordance with the ethical standards of the Declaration of Helsinki.
Participant sample. Elite male players $(n=70)$, from the same professional football club in four age group categories (U16: height $176.7 \pm 5.1 \mathrm{~cm}$, body mass $72.2 \pm 6.9 \mathrm{~kg}$, U17: height $177.8 \pm 7.0 \mathrm{~cm}$, body mass $73.4 \pm 7.2 \mathrm{~kg}$, U19: height $179.1 \pm 6.3 \mathrm{~cm}$, body mass $74.4 \pm 7.3 \mathrm{~kg}$, and U21: height $179.7 \pm 8.1 \mathrm{~cm}$, body mass $75.0 \pm 6.7 \mathrm{~kg}$ ) volunteered to participate in the study. All participating teams played in the highest $* * *$ hidden, will be added after review $* * *$ division and their finished in top 3 highest domestic league.

The average years of football training experience for each group was: U16: $9.1 \pm 2.8$ years, U17: $10.3 \pm 2.1$ years, U19: $11.4 \pm 3.0$ years, and U21: $13.4 \pm 3.3$ years. The mean \pm standard deviation of the age and an overview of the typical weekly training/match frequency in-season is shown in Table I. In order to eliminate potential confounders as much as possible, following information were asked for all players prior to their participation in the research: any knee surgery due to injury through entire career, strenuous physical activity before measurement (48 hours), $90 \%$ of training and match availability for the last two months before measurement, experience of previous isokinetic test(s).

\section{Data collection}

Anthropometric data. Body height was measured using a digital stadiometer (SECA 242, Hamburg, Germany) and body mass was measured using a digital scale (SECA 769, Hamburg, Germany). To maintain consistent data collection procedures, data were collected in the morning (8.00-9.00 a.m.) before light breakfast prior to beginning of measurement for all players.

Isokinetic dynamometry. Isokineticstrength evaluation (ISE) with $90^{\circ} \mathrm{knee}$ flexion/extension of knee extensors (KE) and flexors (KF) was performed by isokinetic dynamometer measurement of the dominant (DL) and nondominant (NL) lower limb while sitting (Cybex NORM®, Humac, CA, USA). Limb dominance was operationally defined as the foot the participant preferred to use to kick the ball. A sixminute warmup at $120 \mathrm{w} / 100 \mathrm{rpm}$ on an ergometer (Excalibur; Lode ${ }^{\circledR}, \mathrm{NL}$ ) and dynamic stretching preceded

Table I. Chronological age and overview of weekly training/match frequency for selected groups (in-season).

\begin{tabular}{llllll}
\hline $\begin{array}{l}\text { Age } \\
\text { Category }\end{array}$ & $\mathrm{N}$ & $\begin{array}{l}\text { Age } \\
\text { (years) }\end{array}$ & $\begin{array}{l}\text { Field-Based } \\
\text { Training }\end{array}$ & $\begin{array}{l}\text { Resistance } \\
\text { Training }\end{array}$ & Match \\
\hline U16 & 20 & $15.7 \pm 0.2$ & $5-6 \times(60-90 \mathrm{~min})$ & $1 \times 30 \mathrm{~min}$ & $2 \times 40 \mathrm{~min}$ \\
U17 & 20 & $16.5 \pm 0.3$ & $5-6 \times(60-90 \mathrm{~min})$ & $1 \times 30 \mathrm{~min}$ & $2 \times 40 \mathrm{~min}$ \\
U19 & 15 & $18.6 \pm 0.4$ & $5-6 \times(60-90 \mathrm{~min})$ & $1 \times 45 \mathrm{~min}$ & $2 \times 45 \mathrm{~min}$ \\
U21 & 15 & $20.3 \pm 0.5$ & $6-7 \times(60-90 \mathrm{~min})$ & $1 \times 45 \mathrm{~min}$ & $2 \times 45 \mathrm{~min}$ \\
\hline
\end{tabular}


ISE. Safety belts were fastened to the torso and distal thigh while seated. Setup of the dynamometer adapter and monorail was set for each participant within gravity correction at $0^{\circ}$. The isokinetic trial protocol was set for five sub-maximal concentric test repetitions at the speed of $60^{\circ} . \mathrm{s}-1$. The diagnostics protocol was set for two maximal concentric test repetitions at the velocity of $60^{\circ}$.s- 1 for the maximal peak torque (PT), ipsilateral ratios of of KE and KF (hamstring to quadriceps; $\mathrm{H}: \mathrm{Q}$ ), and bilateral strength ratios $(\mathrm{Q}: \mathrm{Q}, \mathrm{H}: \mathrm{H})$ evaluation. To achieve rational comparison of isokinetic strength between different age groups, we expressed strength in relative values (normalised to body mass). The procedure was accompanied by verbal encouragement and visual feedback.

Statistical Analyses. Descriptive statistics was applied to all depended variables (mean, standard deviation and shape represented by skewness and kurtosis).A Shapiro-Wilks test was used to evaluate the normality of data distribution. Any data with the higher value of the mean \pm 2 standard deviations were treated as an outlier and excluded from the analysis.Differences in the observed dependent variables between groups were assessed using multivariate analysis of variance (MANOVA). Bonferroni post-hoc tests were used for betweengroup comparisons. The statistical significance level was set at $p=0.05$ and the effect size was assessed using the 'partial Eta square' coefficient (hp2). The coefficient values, $<0,010=$ small, $0.011-0.059=$ small to medium, $0.060-0.138=$ medium to large, and $>0,139=$ large (Sugimoto et al., 2018). The effect size between the means of the MS parameters was assessed by Cohen's coefficient of effect size 'd' (Cohen, 1992). The coefficient value was assessed as follows: $\mathrm{d}=0.20$ - small effect, $\mathrm{d}=0.50-$ medium effect, and d = 0.80 - large effect. Statistical analysis was performed using IBM® SPSS® v24 (Statistical Package for Social Science, Inc., Chicago, IL, 2012).

\section{RESULTS}

Isokinetic strength of knee extensors. The independent variable (age) had a significant effect on PTKE $(\mathrm{F} 3,142=4.54, \mathrm{p}=0.005$, = 0.09). The main factor, laterality, did not have a significant influence on PTKE $(\mathrm{F} 1,142=0.96, \mathrm{p}=0.329,=0.01)$. The interaction between both main factors was also insignificant $(\mathrm{F} 3,142=0.582, \mathrm{p}=0.628$, $=0.01$ ). The U21 players had significantly higher PTKE (up to 8.6 $\%)$ on nondominant leg $(2.92 \pm 0.30 \mathrm{~N} \cdot \mathrm{m} \cdot \mathrm{kg}-1)$ compared toU16 players $(2.67 \pm 0.31 \mathrm{~N} \cdot \mathrm{m} \cdot \mathrm{kg}-1)$ (Table II, Fig. 1).

Isokinetic strength of knee flexors. With increasing age, we found a significant increase in PTKF (Age: F3,142 = 3.07, $\mathrm{p}=0.030$, = 0.06 ) but post hoc analysis did not reveal differences between groups. We did not find significant differences in PTKF between the dominant and nondominant leg (Laterality: F1, 142 =0.23, $\mathrm{p}=0.636,=0.02$ ). No significant interaction effect between both factors was found $(\mathrm{F} 3,142=0.74, \mathrm{p}=0.529,=0.02)$. Strength of knee flexors and their comparison between groups and laterality are presented in Table III and Figure 2.

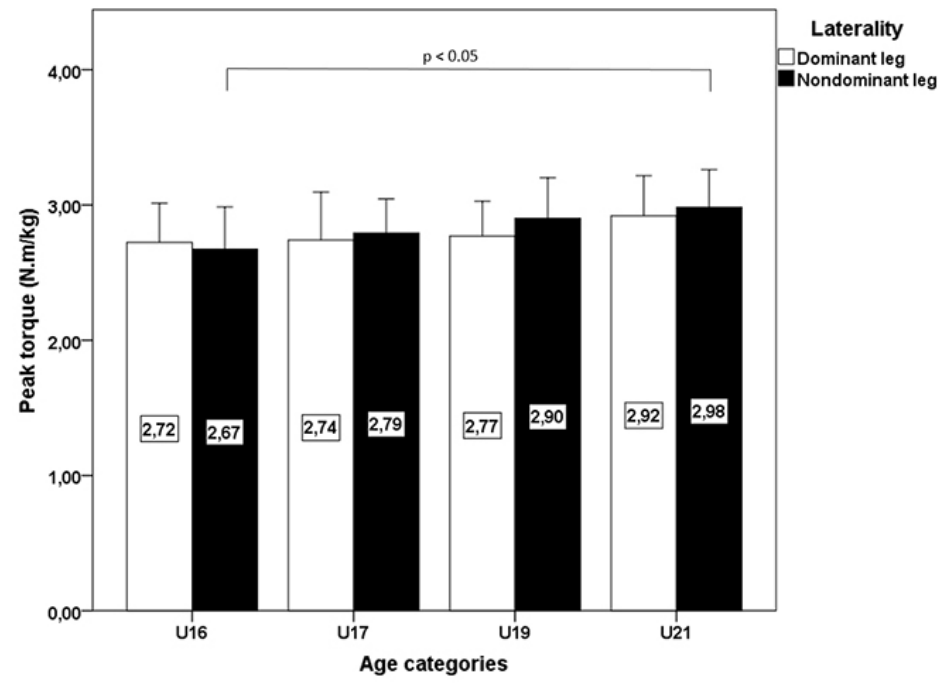

Fig. 1. Comparison of knee extensor strength between groups and limbs.

Table II. Peak muscle torque of knee extensors (PTKE), normalised to body weight $(\mathrm{N} \cdot \mathrm{m} \cdot \mathrm{kg}-1)$.

\begin{tabular}{cccccccc}
\hline \multirow{2}{*}{ Age Category } & \multicolumn{2}{c}{ Dominant Leg } & \multicolumn{2}{c}{ Nondominant Leg } & \multicolumn{3}{c}{ Effect Size } \\
& mean & SD & mean & SD & & $\mathrm{d}$ & Size \\
\hline U16 & 2.72 & 0.29 & $2.67^{\ddagger}$ & 0.31 & 0.591 & 0.17 & small \\
U17 & 2.74 & 0.36 & 2.79 & 0.25 & 0.574 & 0.17 & small \\
U19 & 2.77 & 0.26 & 2.90 & 0.30 & 0.213 & 0.47 & medium \\
U21 & 2.92 & 0.30 & $2.98^{\ddagger}$ & 0.28 & 0.560 & 0.22 & small \\
\hline
\end{tabular}

Legend: $\$-$ significant difference between $\mathrm{U} 16$ and U21, SD - standard deviation, $\mathrm{p}$ - probability of significant differences compared means, $d$ - Cohen's coefficient of effect size. 


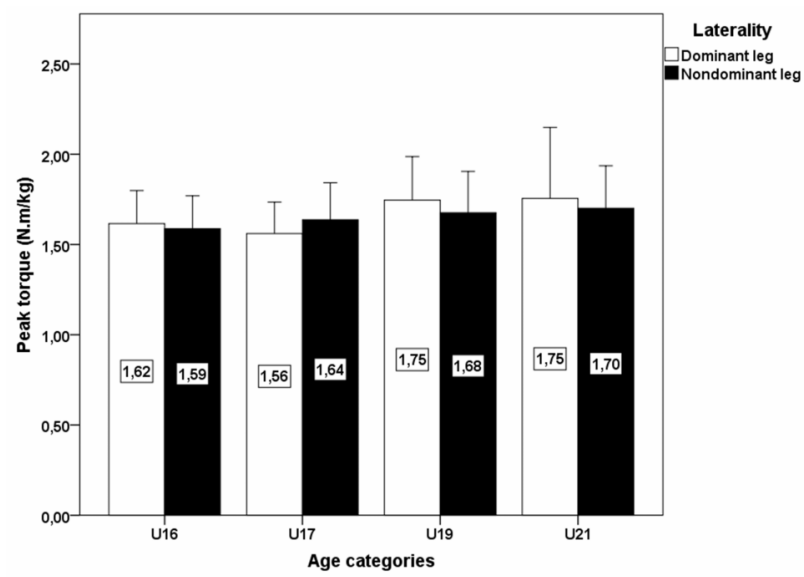

Fig. 2. Comparison of knee flexor strength among groups and limbs.

Bilateral strength ratio. No significant effect of age (F3,142 $=1.05, \mathrm{p}=0.375,=0.02)$ or muscle groups $(\mathrm{F} 1,142=2.418$, $\mathrm{p}=0.122,=0.02$ ) was detected in the studied athletes (Table IV, Fig. 3). The interaction effect between two main factors was insignificant $(\mathrm{F} 3,142=0.35, \mathrm{p}=0.788,=0.01)$. In older players (U17, U19, U21), we observed higher strength asymmetries in knee flexors, but the differences were not significant $(\mathrm{p}>0.05)$.

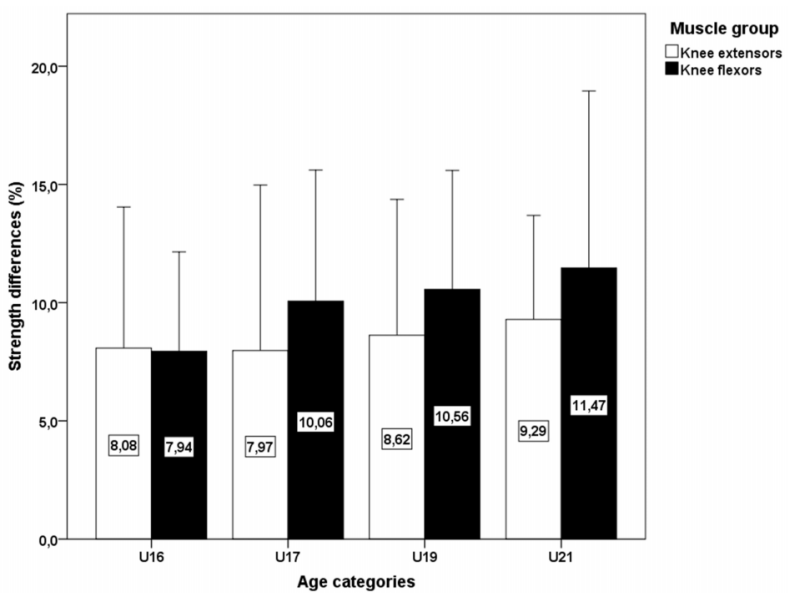

Fig. 3. Comparison of bilateral strength ratios between knee extensors and flexors.

Ipsilateral strength ratios. The independent variable (age) had no significant effect on unilateral strength ratio differences $(\mathrm{F} 3,142=2.63, \mathrm{p}=0.053,=0.06)$. Similarly, the second main factor 'laterality' did not have any significant influence on unilateral strength ratios $(\mathrm{F} 1,142=2.87, \mathrm{p}=$ $0.092,=0.02)$. The interaction between both main factors was not significant $(\mathrm{F} 3,142=1.06, \mathrm{p}=0.370$, $=0.02)$. Bonferroni post hoc analysis only revealed significant

Table III. Peak muscle torque of knee flexors (PTKF), normalised to body weight $\left(\mathrm{N} \cdot \mathrm{m} \cdot \mathrm{kg}^{-1}\right)$.

\begin{tabular}{cccccccc}
\hline \multirow{2}{*}{ Age category } & \multicolumn{2}{c}{ Q:Q ratio } & \multicolumn{2}{c}{ H:H ratio } & \multicolumn{2}{c}{ Effect Size } \\
& mean & SD & mean & SD & d & d & Small \\
\hline U16 & 8.08 & 5.97 & 7.94 & 4.20 & 0.942 & 0.03 & small \\
U17 & 7.97 & 7.00 & 10.06 & 5.55 & 0.254 & 0.33 & medium \\
U19 & 8.62 & 5.75 & 10.56 & 5.03 & 0.343 & 0.36 & medium \\
U11 & 9.29 & 4.40 & 11.47 & 7.48 & 0.303 & 0.36 &
\end{tabular}

$\mathrm{d}$ - Cohen's coefficient of effect size.

Table IV. Bilateral strength ratios between knee extensors (QQ) and flexors (HH).

\begin{tabular}{|c|c|c|c|c|c|c|c|}
\hline \multirow{2}{*}{ Age Category } & \multicolumn{2}{|c|}{ Dominant Leg } & \multicolumn{2}{|c|}{ Nondominant Leg } & \multirow{2}{*}{$\mathrm{p}$} & \multicolumn{2}{|c|}{ Effect Size } \\
\hline & mean & SD & mean & SD & & $\mathrm{d}$ & Size \\
\hline U16 & 1.62 & 0.18 & 1.59 & 0.18 & 0.591 & 0.15 & small \\
\hline U17 & 1.56 & 0.17 & 1.64 & 0.20 & 0.574 & 0.40 & medium \\
\hline U19 & 1.75 & 0.24 & 1.68 & 0.23 & 0.213 & 0.30 & small \\
\hline $\mathrm{U} 21$ & 1.75 & 0.39 & 1.70 & 0.24 & 0.560 & 0.17 & small \\
\hline
\end{tabular}

d-Cohen's coefficient of effect size.

Table V. Unilateral strength ratios in dominant and nondominant legs.

\begin{tabular}{ccccccrrr}
\hline \multirow{2}{*}{ Age category } & \multicolumn{2}{c}{ Dominant Leg } & \multicolumn{2}{c}{ Nondominant Leg } & \multicolumn{2}{c}{ Effect Size } & \multicolumn{2}{c}{ Size } \\
\hline U16 & 60.62 & 7.75 & 59.67 & 8.29 & 0.682 & 0.12 & small \\
U17 & 57.02 & 7.02 & 57.57 & 5.42 & 0.814 & 0.09 & small \\
U19 & 64.58 & 6.34 & 59.20 & 5.95 & 0.039 & 0.88 & large \\
U21 & 59.79 & 9.73 & 57.18 & 7.46 & 0.330 & 0.30 & small \\
\hline
\end{tabular}

d-Cohen's coefficient of effect size. 
differences between dominant and nondominant leg in players of the U19 category $(\mathrm{p}=0.039)$. Descriptive data and their mutual comparison are presented in Table $\mathrm{V}$ and Figure 4.

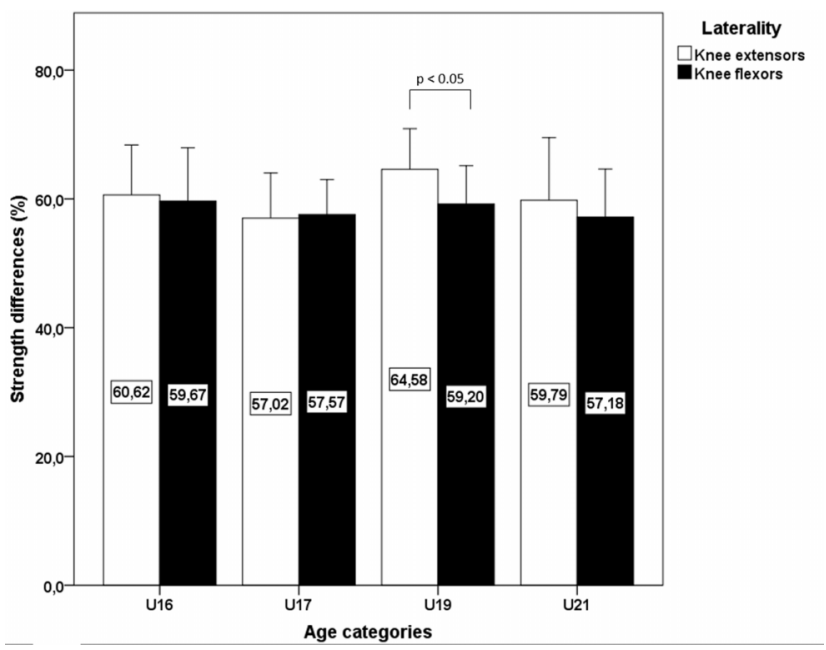

Fig. 4. Comparison of unilateral strength ratios between dominant and nondominant limbs.

\section{DISCUSSION}

Our study revealed significant effect of age on knee extensor and flexor strength among measured groups. However, age had not significant influence on bilateral strength asymmetries or ipsilateral strength ratios. Finally, there was no effect of laterality on isokinetic strength and strength parameters.

Effect of age on isokinetic strength. Present study revealed a significant effect of age on PTKE between the observed groups. The oldest players (U21) produced greater strength compared to younger players (U16) (Table II). MS differences between U21 and U16 were $6.9 \%$ in the preferred leg and $10.4 \%$ (significant difference) in the non-preferred leg. However, significant differences were not found among U16, U17, and U19 groups. Participants in this study (U17, U21) demonstrated lower MS than players from the Belgian First Division as reported by Lehance et al. In the U17 category, the authors reported greater strength in the dominant leg up to $7.7 \%(2.97 \pm 0.24 \mathrm{~N} \cdot \mathrm{m} \cdot \mathrm{kg}-1)$ and in the nondominant leg up to $9.7 \%(3.09 \pm 0,22 \mathrm{~N} \cdot \mathrm{m} \cdot \mathrm{kg}-1)$. Similarly, knee extensor values were higher in U21 category of the Belgian First Division team compared to our study participants (dominant leg: $4.6 \%$, PTKE $=3.06 \pm 0.44 \mathrm{~N} \cdot \mathrm{m} \cdot \mathrm{kg}-1$, nondominant leg: $7.5 \%, \mathrm{PTKE}=3.22 \pm 0.44 \mathrm{~N} \cdot \mathrm{m} \cdot \mathrm{kg}-1)$. Further, higher values of isokinetic strength were reported by Kellis et al. (2001) in Greek football players in the U16 and U17 category. In terms of knee flexor strength, we found a significant effect of age on isokinetic strength. The oldest players (U19 and U21) achieved almost the same level as that of MS performance (Tables II and III).

If we express MS in relative values, it is possible that the older age category achieves higher values of PTKF in comparison to the younger category, probably because of the maturation (De Ste Croix et al., 2001). However, in our study, U17 players showed lower strength of KFs in the dominant limb $(1.56 \pm 0.18 \mathrm{~N} \cdot \mathrm{m} \cdot \mathrm{kg}-1)$ than U16 players $(1.62 \pm 0.18$ $\mathrm{N} \cdot \mathrm{m} \cdot \mathrm{kg}-1$ ), but not in the nondominant. Similar results also appeared in other studies examining football players (Kellis et al.; Lehance et al.). Lehance et al. presented significantly higher muscle strength of KEs in professional adult players $(224.2 \pm 38.8 \mathrm{~N} \cdot \mathrm{m})$ in comparison to the U17 category (194.7 $\pm 23.6 \mathrm{~N} \cdot \mathrm{m})$. However, no significant differences in MS performance were observed after the normalisation for body mass parameters (adults: $2.98 \pm 0.35 \mathrm{~N} \cdot \mathrm{m} \cdot \mathrm{kg}-1$ vs. U17: $2.97 \pm$ $0.24 \mathrm{~N} \cdot \mathrm{m} \cdot \mathrm{kg}-1)$. These results confirmed the importance of controlling the morphological aspects linked to the level of MS in high performance athletes.

The results of the present study revealed that players approximately 17 years old did not show any significant differences in peak torques (extensors, flexors) compared to their older players (U19, U21) teammates. Our results are in line with a study by Lehance $e t$ al. who reported that 17 year-old highly trained players have already reached a MS very close to the level of adult players. Growing strength of lower limbs, based on the aging factor, is highly influenced by the type, volume, and quality of the physical activity overall (De Ste Croix et al.; Maly et al., 2019), and it seems that football-specific training is beneficial for the relative strength ratios for dominant and nondominant legs (Lehance et al.; Kellis et al.).

Age-related differences within isokinetic strength of elite youth football players' lower limbs were evaluated in many studies (Kellis et al.; Forbes et al., 2009; Lehnert et al., 2011; Bona et al., 2017; Eustace et al., 2019; Zahalka et al., 2019). In summary, part of the studies reported a significant effect of age on isokinetic strength of players; however, another part of the findings is inconsistent. Various results could be explained by different performance levels of players, or missing information about strength and conditioning programme(if some) during training cycles, or period of testing players (preseason, in-season).

Investigations conducted by Bona et al. and Kellis et al. suggested that there is a positive association between increased chronological ages and the greater absolute and relative PT force in well-trained elite football players. 
However, Eustace et al. reported an insignificant effect of age on isokinetic strength between PT of the elite senior group (age $25.09 \pm 3.83$ years) and the youth group (age $17.00 \pm$ 0.06 years). In contrast, a study by Lehnert et al. aimed at comparing unilateral isokinetic knee PT strength at $60^{\circ}, 180^{\circ}$, and $300^{\circ} . \mathrm{s}-1$ between U16, U17, and U18 elite football players; significant difference was found between the age groups for flexors and extensors at the $60^{\circ}$ and $180^{\circ} . \mathrm{s}-1$ speed.

Reviewing literature, it is important to distinguish between studies that consider absolute values of strength (Kellis et al.; Forbes et al.; Lehance et al.; Lehnert et al.; Bona et al.) and those that used normalised values (Lehanceet al.; Forbes et al.). For instance, no significant effect of age between U15, U16, and U18 players was found when data were normalised to body mass by Forbes et al. In the current study, we also did not confirm any significant differences between U16, U17, and U19 when strength was expressed in normalised values. A few investigators stated that age-related changes in strength cannot be wholly explained just by changes in body weight; body size plays an important role in the level of strength, because bigger individuals are usually stronger (De Ste Croix et al.). De Ste Croix et al. concluded that age is a non-significant explanatory variable of isokinetic knee torque, once stature and mass were accounted for. Another potential explanation could be associated with body composition changes during growth and maturation. Results from a recent study by Mala et al. (2020) confirms the end of height growth around the age of 16 years in male football players, while weight continues to increase until 20 years. This increase is not linked to neither decreasing fat mass, nor to the fat free mass which remains stable. It is, rather, an increase in bone mass.

Laterality. Laterality did not reveal any significant differences between the compared limbs. Previous studies also showed inconsistent findings. Insignificant findings between the DL and NL are in line with several studies (Kellis et al.; Rahnama et al., 2005). In contrast, other studies revealed significant differences between lower limbs in favour of the DL (Fousekis et al.; Bona et al.) although there were significant differences in favour of the NL as well in some age categories (Fousekis et al.).

Bilateral strength ratio. Bilateral strength ratio for extensors varied between $7.97 \%$ and $9.29 \%$, while the range for flexors was wider (7.94-11.47\%). Our results did not confirm a statistically significant effect of age on bilateral strength ratio in four age categories (Table IV), or on muscle groups (Q:Q vs H:H). Particularly, in older players (U19, U21), we found medium effect size when we compared bilateral strength differences between flexors and extensors. This is in the line with a study by Magalhães et al. (2004) that reported a higher bilateral strength difference for flexors $(\mathrm{H}: \mathrm{H}$ $=10.6 \pm 8.0 \%)$ compared to extensors $(\mathrm{Q}: \mathrm{Q}=7.3 \pm 6.5 \%)$ in adult players. In contrast, Maly et al. (2019) reported similar results of strength asymmetries between extensors and flexors $(\mathrm{Q}: \mathrm{Q}=10.99 \pm 7.75 \%, \mathrm{H}: \mathrm{H}=10.86 \pm 8.44 \%)$ in younger players (15 years old). Lower values of bilateral strength ratios compared to our study have been reported by Bona et al. in Brazilian players (U17 category) (Q:Q = 6.2 \pm $4.7 \%, \mathrm{H}: \mathrm{H}=6.8 \pm 4.9 \%$ ). One of the factors that could contribute to the increase of a bilateral difference in older players can be their specialisation, since the activity with the dominant leg for side positions (fullbacks, wide midfielders, wingers) is more preferred. This may be connected with greater activation of particular muscle groups (passes on short and middle distances and cross passes).

Ipsilateral strength ratio. Our study revealed an insignificant effect of age and laterality on unilateral strength ratio (HQ) between the observed groups and leg preferences. The ratio varied between $57.18 \%$ and $64.58 \%$. This is in line with the statement by Baroni et al. (2020) who reported, based on a systematic review study, that the mean HQ ratio is closer to $60 \%$ in professional adult players $(\mathrm{n}=1727)$. Our results are consistent with a study by Forbes et al. who reported no significant effect of age between groups of players from U12 to U18 ( $p>0.05)$.

Due to the repetitive nature of football-specific activities, the magnitude of MS enhancement may help greater quadriceps muscle development compared to hamstrings. Croisier et al. (2008) reported that players with strength imbalances were four to five times more likely to sustain a hamstring injury when compared with players without strength imbalances, thus we also endorse the need for regular MS monitoring.

In addition, determining the balance between agonist and antagonist muscle groups significantly reduces the risk of injury. Furthermore, Lehance et al. found a greater percentage of lower limb muscle imbalance in younger players ( $<17$ years old, $61 \%$ and $<21$ years old, $58 \%$ ) than in adult players $(50 \%)$, stating that a targeted training process reduces muscle imbalance and consequent risk of injury.

Despite the efforts of scientists and clinical staff to address this issue, the topic of strength asymmetry is still up to date in terms of both performance and identification and prevention of possible injury or injury recurrence. In recent research, Hart et al. (2019) reported significant differences in strength parameters in a jump test even for players returning to play 12 months after injury. Residual inter-limb deficits are a potential contributing factor leading to compensatory movement patterns during the training process. 
Low bilateral and unilateral asymmetries in elite youth football players detected in our study could be explained by the following reasons: All observed athletes were recruited from one professional team and each team has at least one physiotherapist on staff. Furthermore, screening of isokinetic strength occurs twice per year by the same examiner and with the same device. If the MS differences appear, the strength and conditioning coach together with the physiotherapist prepare a tailored program for the player. In all age categories, strength training is provided at least once per week as part of a regular strength program with unilateral exercises such as Romanian dead lifts; Bulgarian split squat; forward, backward, side lunges; single leg squats, and 'pistol' squats.

Study limitations. The study limitations include testing at low angular velocity $\left(60^{\circ}\right.$.s-1) with concentric muscle contraction only. Furthermore, players' biological age was not considered, i.e., the relationship between testosterone and growth hormone production as a covariant factor or as a criterion for assigning players into groups. Another limitation of our study is the comparison of parameters regardless of different playing positions. Moreover, we tested players just in preseason.

Moreover, in further research, it is desirable to focus on players' biological age, although, in our study, players from the same club were assigned to age categories (chronological age). Another option could be to sort players according to the bio-banding principle.

\section{CONCLUSIONS}

Football frequently involves one-sided activities such as kicking, tackling, and passing that may lead to strength asymmetries. Our study showed that elite 17-year-old players have similar levels of strength compared to older players. With increasing age, we found a significant increase in knee flexor strength, but post hoc analysis did not reveal differences between groups.

The effect of laterality was not statistically confirmed in any of the observed categories even for one measured parameter. Greater bilateral difference of knee flexors than extensors was found, suggesting that more attention should be paid to them in terms of regular muscle strength diagnostics and evaluation of potential risk of injury indicators, such as rising tendency of bilateral and unilateral strength asymmetry may be.Despite insignificant findings, medium effect size was found in greater bilateral differences in knee flexors in the older categories (U19, U21).
Players' ages did not have a significant effect on the unilateral ratio of MS. We have also found a large effect size in unilateral strength ratio between legs in the U19 category.

\section{ACKNOWLEDGMENTS}

This study was supported by GACR19-12150S, UNCE HUM/032

MALY, T.; FORD, K. R.; SUGIMOTO, D.; IZOVSKA, J.; BUJNOVSKY, D.; HANK, M.; CABELL, L. \& ZAHALKA, F. Fuerza isocinética, diferencias de fuerza bilaterales y unilaterales: variación por edad y lateralidad en futbolistas juveniles de élite. Int. J. Morphol., 39(1):260-267, 2021.

RESUMEN: El objetivo de este estudio fue investigar el efecto de la edad en las medidas de fuerza relativa de torque máximo (TM) de los extensores de rodilla (ER) y flexores de rodilla (FR), la relación de fuerza bilateral (Q: Q, H: H) y la relación de fuerza ipsilateral (H: Q) en jugadores de fútbol masculino de élite en 70 sujetos de cuatro categorías de edad (U16: $n=20$, U17: $n=$ 20, U19: $\mathrm{n}=15, \mathrm{U} 21: \mathrm{n}=15)$. Se realizaron pruebas de fuerza isocinética utilizando un dinamómetro Cybex. Los resultados mostraron un efecto significativo de la edad en TMER $(\mathrm{F} 3,142=4,54$, $\mathrm{p}=0,005,=0,09)$ y TMFR (edad: age: F3,142 =3,07, p = 0,030, $=0,06)$. No se observó efecto significativo alguno de la edad sobre la fuerza unilateral $(\mathrm{F} 3,142=1,05, \mathrm{p}=0,375,=0,02) \mathrm{o}$ relación de fuerza ipsilateral $(\mathrm{F} 3,142=2,63, \mathrm{p}=0,053,=0,06)$. Los resultados indicaron diferencias significativas en TMER para miembros no dominantes entre U16 y U21. Se detectaron mayores diferencias bilaterales para los flexores $(\mathrm{H}: \mathrm{H}=7,94-11,47$ $\%, \mathrm{Q}: \mathrm{Q}=7,97-9,29 \%$ ) en comparación con los extensores. Nuestro estudio mostró que los jugadores de 17 años tienen niveles de fuerza similares a la de los jugadores sub-19. Se observó una mayor diferencia bilateral de flexores de rodilla que de extensores, lo que sugiere que se debe prestar más atención a los flexores de rodilla. No se encontró un efecto de lateralidad para fuerza y asimetrías de fuerza. Los estudios futuros también deben centrarse en la relación de fuerza ipsilateral en la etapa tardía de maduración.

PALABRAS CLAVE: Fútbol; Actuación; Asimetrías de fuerza; Prevención de lesiones.

\section{REFERENCES}

Aagaard, P.; Simonsen, E. B.; Andersen, J. L.; Magnusson, P. \& DyhrePoulsen, P. Increased rate of force development and neural drive of human skeletal muscle following resistance training. J. Appl. Physiol. (1985), 93(4):1318-26, 2002.

Baroni, B. M.; Ruas, C. V.; Ribeiro-Alvares, J. B. \& Pinto, R. S. Hamstringto-quadriceps torque ratios of professional male soccer players: a systematic review. J. Strength Cond. Res., 34(1):281-93, 2020. 
Bona, C. C.; Tourinho Filho, H.; Izquierdo, M.; Ferraz, R. M. P. \& Marques, M. C. Peak torque and muscle balance in the knees of young U15 and U-17 soccer athletes playing various tactical positions. J. Sports Med. Phys. Fitness, 57(7-8):923-9, 2017.

Bourne, M. N.; Opar, D. A.; Williams, M. D. \& Shield, A. J. Eccentric knee flexor strength and risk of hamstring injuries in rugby union: a prospective study. Am. J. Sports Med., 43(11):2663-70, 2015.

Clemente, F. M. Small-sided and Conditioned Games in Soccer Training: The Science and Practical Applications. Singapore, Springer Verlag, 2016.

Cohen, J. A power primer. Psychol. Bull., 112(1):155-9, 1992.

Croisier, J. L.; Ganteaume, S.; Binet, J.; Genty, M. \& Ferret, J. M. Strength imbalances and prevention of hamstring injury in professional soccer players: a prospective study. Am. J. Sports Med., 36(8):1469-75, 2008.

De Ste Croix, M. B.; Armstrong, N.; Chia, M. Y.; Welsman, J. R.; Parsons, G. \& Sharpe, P. Changes in short-term power output in 10- to 12-yearolds. J. Sports Sci., 19(2):141-8, 2001.

Eustace, S. J.; Page, R. M. \& Greig, M. Isokinetic strength differences between elite senior and youth female soccer players identifies training requirements. Phys. Ther. Sport., 39:45-51, 2019.

Forbes, H.; Bullers, A.; Lovell, A.; McNaughton, L. R.; Polman, R. C. \& Siegler, J. C. Relative torque profiles of elite male youth footballers: effects of age and pubertal development. Int. J. Sports Med., 30(8):5927, 2009.

Fousekis, K.; Tsepis, E. \& Vagenas, G. Lower limb strength in professional soccer players: profile, asymmetry, and training age. J. Sports Sci. Med., 9(3):364-73, 2010.

Hart, L. M.; Cohen, D. D.; Patterson, S. D.; Springham, M.; Reynolds, J. \& Read, P. Previous injury is associated with heightened countermovement jump force-time asymmetries in professional soccer players. Transl. Sports Med., 2(5):256-62, 2019.

Iga, J.; George, K.; Lees, A. \& Reilly, T. Cross-sectional investigation of indices of isokinetic leg strength in youth soccer players and untrained individuals. Scand. J. Med. Sci. Sports, 19(5):714-9, 2009.

Kellis, S.; Gerodimos, V.; Kellis, E. \& Manou, V. Bilateral isokinetic concentric and eccentric strength profiles of the knee extensors and flexors in young soccer players. Isokinet. Exerc. Sci., 9:31-9, 2001.

Lehance, C.; Binet, J.; Bury, T. \& Croisier, J. L. Muscular strength, functional performances and injury risk in professional and junior elite soccer players. Scand. J. Med. Sci. Sports, 19(2):243-51, 2009.

Lehnert, M.; Urban, J.; Procházka, J. H. \& Psotta, R. Isokinetic strength of knee flexors and extensors of adolescent soccer players and its changes based on movement speed and age. Acta Gymn., 41:45-53, 2011.

Lloyd, R. S.; Faigenbaum, A. D.; Stone, M. H.; Oliver, J. L.; Jeffreys, I.; Moody, J. A.; Brewer, C.; Pierce, K. C.; McCambridge, T. M.; Howard, R.; et al. Position statement on youth resistance training: the 2014 International Consensus. Br. J. Sports Med, 48(7):498-505, 2014.

Magalhães, J.; Oliveira, J.; Ascensão, A. \& Soares, J. Concentric quadriceps and hamstrings isokinetic strength in volleyball and soccer players. $J$. Sports Med. Phys. Fitness, 44(2):119-25, 2004.

Mala, L.; Maly, T.; Cabell, L.; Hank, M.; Bujnovky, D. \& Zahalka, F. Anthropometric, body composition, and morphological lower limb asymmetries in elite soccer players: a prospective cohort study. Int. J. Environ. Res. Public Health, 17(4):1140, 2020.

Maly, T.; Mala, L.; Bujnovsky, D.; Hank, M. \& Zahalka, F. Morphological and isokinetic strength differences: bilateral and ipsilateral variation by different sport activity. Open Med. (Wars.), 14:207-16, 2019.

Maly, T.; Sugimoto, D.; Izovska, J.; Zahalka, F. \& Mala, L. Effect of muscular strength, asymmetries and fatigue on kicking performance in soccer players. Int. J. Sports Med., 39(4):297-303, 2018.

Maly, T.; Zahalka, F. \& Mala, L. Unilateral and ipsilateral strength asymmetries in elite youth soccer players with respect to muscle group and limb dominance. Int. J. Morphol., 34(4):1339-44, 2016.

Rahnama, N.; Lees, A. \& Bambaecichi, E. Comparison of muscle strength and flexibility between the preferred and non-preferred leg in English soccer players. Ergonomics, 48(11-14):1568-75, 2005.
Suchomel, T. J.; Nimphius, S. \& Stone, M. H. The importance of muscular strength in athletic performance. Sports Med., 46(10):1419-49, 2016.

Sugimoto, D.; McCartney, R. E.; Parisien, R. L.; Dashe, J.; Borg, D. R. \& Meehan 3rd, W. P. Range of motion and ankle injury history association with sex in pediatric and adolescent athletes. Phys. Sports Med., 46(1):24-9, 2018.

Wild, C. Y.; Steele, J. R. \& Munro, B. J. Insufficient hamstring strength compromises landing technique in adolescent girls. Med. Sci. Sports Exerc., 45(3):497-505, 2013.

Xaverova, Z.; Dirnberger, J.; Lehnert, M.; Belka, J.; Wagner, H. \& Orechovska, K. Isokinetic strength profile of elite female handball players. J. Hum. Kinet., 49:257-66, 2015.

Zahalka, F.; Maly, T.; Ford, K. R.; Sugimoto, D.; Mala, L.; Gryc, T. \& Mikesova, V. Lower extremity force production and postural stability changes with age in young male soccer players. Med. Sci. Sports Exerc., 51:63, 2019.

Zahalka, F.; Maly, T.; Mala, L. \& Cabell, L. A new approach to determining performance in vertical jumps in professional soccer players. Med. Sci. Sports Exerc., 48:790, 2016.

\section{Corresponding author: \\ Tomas Maly \\ Jose Martiho 31 \\ Prague \\ CZECH REPUBLIC}

Email: maly@ftvs.cuni.cz

Received: 24-08-2020

Accepted: 17-09-2020 